\title{
An AAC Mobile-Based Application for People with Intellectual Disability: A Case Study in Brazil
}

\author{
Mauro José Conte, ${ }^{1}$ Marcelo Gitirana Gomes Ferreira, ${ }^{2}$ and Alejandro R. García Ramírez (iD ${ }^{1}$ \\ ${ }^{1}$ Department of Applied Computing, University of Vale de Itajai, Uruguai Av., 458, CEP 88302-901, Itajai, SC, Brazil \\ ${ }^{2}$ Department of Design, State University of Santa Catarina, Santa Monica Av., 1907, CEP 88.035-901, Florianópolis, SC, Brazil
}

Correspondence should be addressed to Alejandro R. García Ramírez; garcia.ramirez@gmail.com

Received 4 September 2019; Revised 19 March 2020; Accepted 13 May 2020; Published 5 June 2020

Academic Editor: Marco Porta

Copyright (c) 2020 Mauro José Conte et al. This is an open access article distributed under the Creative Commons Attribution License, which permits unrestricted use, distribution, and reproduction in any medium, provided the original work is properly cited.

\begin{abstract}
Augmentative and Alternative Communication (AAC) techniques are employed to mediate communication with people who have communication disorders, as in cases of intellectual disability. Although there are various digital solutions that promote alternative communication options for individuals with communication disorders, only a few of them have been specifically designed or targeted to people with intellectual disability (ID). This work is motivated by the lack of AAC solutions contributing to the rehabilitation processes of individuals with intellectual disability in Brazil. The study presents a mobile-based AAC solution conceived as a tool to assist the rehabilitation process of people with ID. The design was based on user-centered design principles and accessibility standards. The System Usability Scale (SUS) questionnaire was used to evaluate the solution. Four specialists and twenty-five students participated in this study. The proposed solution shows the potential educational value for professionals who assist individuals with intellectual disability in Brazil.
\end{abstract}

\section{Introduction}

A study released by the World Health Organization (WHO) revealed that more than 1 billion people worldwide have some sort of disability and the number of individuals with disability tends to increase due to population growth and aging [1]. However, only a few countries have implemented impactful mechanisms to effectively assist disabled people. The barriers most commonly faced by disabled people include discrimination, inadequate health care and rehabilitation services, and lack of accessibility. Governments should also work to sensitize society, supporting the research and training of professionals who take care of people with disabilities. In this context, Brazil made initial efforts to improve access for people with disabilities to basic services, adopting strategies for this section of the community [2].

In Brazil, according to the Brazilian Institute of Geography and Statistics (IBGE) [3], there are about 45 million people with disabilities, which represent approximately 24 percent of the whole population. The national plan for establishing rights of persons with disabilities, known as Living without Barriers, launched by Dilma Rousseff on 17 November 2011 (Decree No. 7.612), promotes programs and actions to guarantee the rights of individuals with disabilities through the articulation and integration of diverse public policies [4]. The National Network to Assistive Technology Research and Development (CNRTA) comprises 90 research centers and 54 institutions. Universities and institutes of science, technology, and education integrate this network. However, in reality, in Brazil, a gap can be observed between technological solutions in this field, driving a continuing investment in supplying technological solutions for professionals and people with special needs.

Recent developments in mobile technology, such as smartphones and tablets, have provided important and new communication tools [5]. The wide availability of powerful portable networking technologies has changed our way of working, learning, our leisure time, and social interaction 
[6]. Mobile technology has advantages over traditional technologies as an inclusive tool [5]. From the author's point of view, there is too much to be done developing mobile applications to fully consider the needs of professionals and students with disabilities. In addition, affordability and costs remain as barriers in this process, and not enough usability evaluations have been conducted so far, particularly in cases of intellectual disability [7].

1.1. What Is Intellectual Disability (ID)? According to the American Association on Intellectual Development Disability (AAIDD), an intelligence quotient (IQ) below the 70-75 range characterizes an intellectual disability [8]. This disability is often associated with adaptive limitations that occur in childhood. It encompasses changes in brain performance and may be caused by genetic factors, problems during pregnancy or childbirth or after birth, or even with no known cause [8]. Individuals with intellectual disability experience constrained development and have difficulties learning and performing daily tasks. These restrictions limit interaction with their peers and with the environment [9]. The Instituto Inclusão Brasil (ITS Brasil) estimates that 87 percent of Brazilian children with intellectual disability have more difficulties learning and acquiring new skills, compared to those without disabilities [4]. New Zealand pioneered the identification and diagnosis of intellectual disability and developed several intervention methods [10].

According to the Diagnostic and Statistical Manual of Mental Disorders (DSM) [11], there are three levels of commitment:

(1) Level 3: "Requiring very substantial support"persons have severe deficits in verbal and nonverbal communication skills; speech is intelligible, but they have great limitation in initiating social interactions; exhibit inflexibility of behavior and extreme difficulty dealing with change

(2) Level 2: "Requiring substantial support"-persons have severe deficits in verbal and nonverbal communication skills; speak simple phrases, characterized by the lack of social interactions; exhibit behavior inflexibility; and manifest some difficulty in dealing with change

(3) Level 1: "Requiring support"-persons show reduced interest in social interactions and can speak complete sentences and be engaged in communication, although they often fail in conversation; attempts to make friendships are unfamiliar and unsuccessful; exhibit difficulty in changing activity and problems dealing with organization and planning tasks

These levels also take living context into account. Family support, a professional multidisciplinary team, and school activities are fundamental to accomplishing the necessary development. The degrees of impairment, as previously mentioned, will reflect on the different approaches and interventions performed on any particular individual. Appropriate behaviors can be learned and it is necessary to know and to understand the learning processes, identifying the difficulties and limitations.

Assistive Technology (AT) could contribute to the rehabilitation of individuals with intellectual disability. AT encompasses a set of solutions designed to enhance or complement functional capabilities of persons with disabilities, promoting independence [9]. Assistive Technology can also be understood as an aid that promotes the expansion of a functional ability or that enables a desired function that is constrained by the disability [12]. Examples of Assistive Technology resources are Alternative and Augmentative Communication (AAC) and Accessible Information and Communication Technologies (ICT).

AAC covers all forms of communication (other than speech) and is used to express needs, desires, and ideas based on facial expressions, gestures, symbols, images, and writing [13]. AAC is essential to the educational process, providing social inclusion, meeting basic needs, making friends, and developing academic skills to better engage individuals in communicative activities within the family and community [14].

The development of AAC resources for education is essential. The Brazilian legislation establishes that basic education is compulsory from ages 4 to 17 years [15]. Because of this, increasing enrollment of students with disabilities in the regular education process is observed. In this regard, there is a need to carry out actions that lead to the independence and academic success of these students. This process is closely linked to the use of AAC methodologies and resources.

An important AAC reference is the Aragonese Portal [16]. In this portal, there is a large symbols library, as well as various graphic resources, didactic materials, and guidelines for specialists and developers of AAC solutions. Nowadays, availability and the cost of solutions are obstacles to overcome. Scala WEB, Classroom Suite, Tobii (Dynavox, Pro, Tech), BoardMaker, Boardmaker with Speaking Dynamically Pro, and Vox4all, are among the most well-known AAC solutions in Brazil.

Many organizations worldwide provide online information resources related to ID. Mind for better mental health in [17] offers support about the treatment and rights of people with mental health problems, as well as sharing everyday stories about how people are living with mental health problems. Mental health in [18] shows evidencebased information on mental health problems, treatments, and other topics written by psychiatrists with help from patients and professionals. Virtual communities, such as Mencap's Family, feature a supportive place to meet others, ask questions about learning disabilities, share experience, and offer support [19]. In Brazil, as far as we know, the only reference to software solutions related to intellectual disability is the Projeto Participar [20].

1.2. Related Studies. A literature review was performed in order to search key elements of AAC solutions designed for ID and usability evaluation. The review was performed through the ISI Web of Science, Scopus, IEEE, and CAPES 
(Brazil) databases prior to 31 May 2019. Searches were undertaken using different variations of the following search strings: ("intellectual disability") and ("alternative communication") and ("Usability"). In total, 305 articles were evaluated considering the title, summary, and keywords. This section presents works related to this study, drawing parallels with current research challenges recognized in the literature.

Matson and Shoemaker in [21] analyze the cognitive obstacles faced in accessing digital technologies for people with intellectual disability. They conclude that it is often a marginalized and socially excluded group, repeatedly excluded from the development and implementation of new interventions, even though they are able and willing to use digital technologies. However, there is a scarcity of empirical data to support the usability of digital solutions. The authors also state that universal design principles should guide the development processes. The ages of the participants ranged from approximately 3 to 17 years.

Sheehan and Hassiotis in [7] explore the use of digital technologies in the rehabilitation practices for people with intellectual disabilities. They present the barriers that people with mental illness face with fully in-depth digital technology and concluded that those barriers may be overcome with appropriate support. According to the authors, there is still "small literature attesting the value of incorporating digital technologies into the lives of people with intellectual disability, not only for promoting health but also for enhancing educational, vocational, and leisure opportunities." Acceptance of newer devices such as tablet computers by people with intellectual disability has not been studied in any depth.

Williams and Sidharth in [22] introduce a literature review of various mobile devices for adults with intellectual, learning, or cognitive disabilities, to determine factors affecting usability and how usability could be enhanced. They are based on efficient-to-use (less time taken to complete any particular task), easier-to-learn (operations can be learned through observation), and user satisfaction factors.

Ebert and Parveen in [23] present research to determine the existing evidence for the use of iPad and mobile devices as the primary language intervention method for children with autism spectrum disorder (ASD). The results of this review suggest that iPads and mobile devices may be effective for language intervention among children with ASD.

Wiley et al. in [24] conducted a study to review data gathered during a pilot project that trialed the use of a tablet computer. Participants presented with a variety of disabilities, including Down syndrome, autism, developmental delay, learning disabilities, genetic disorders, cerebral palsy, hearing loss, behavioral concerns, and traumatic brain injury from childhood stroke. The study reviewed quantitative and qualitative data collected during the sessions, which included data regarding students' level of engagement and "overall ability to learn how to operate mobile devices and its applications." Results were positive for "level of engagement" and "ease of use" with cause and effect applications. For lower-functioning students, or students not previously exposed to tablet technology, scores were lower. Likert 5point scaling was used [24].
Yeni et al. in [25] examined the usability of an interactive mobile (tablet) application designed to teach daily living skills to individuals with intellectual disabilities. One male and four females with a diagnosis of intellectual disability took part in the study. Effectiveness, efficiency, and satisfaction aspects were investigated. Five professionals evaluated the satisfaction levels using the tablet application. The results show that using interactive tablet applications in the education of individuals with ID could be an effective method to improve their motor skills and support selfconfidence.

Cáliz et al. in [26] reviewed the usability testing of mobile applications in participants with Down syndrome (DS). People with DS have impaired cognitive processing, language learning, and physical abilities, as well as different personal and social characteristics. The main finding of this work is that mobile application usability testing in people with Down syndrome is an issue that has not been comprehensively investigated so far. The authors proposed guidelines for the usability testing procedure involving participants with Down syndrome.

Carniel et al. in [27] discuss how Augmentative and Alternative Communication (AAC) can be used to support dialog with people with intellectual disabilities. The authors present a literature survey conducted in the academic databases Science Direct, ACM, and IEEE. They found research for autism (18), cerebral palsy (9), aphasic (5), multiple disabilities (2), dysarthria (1), and intellectual disability (1). The use of tablets stands out as the most used device, appearing in 51 percent of the solutions. The instrument most used for validation purposes was the "user observation" (i.e., user analysis interacting with the system). The authors do not identify a standard regarding the metrics used and only one work was collaborative.

Alzrayer and Nouf in [28] analyze the effects of using iPads ${ }^{\circledR}$ in teaching multistep social communication skills to children with autism spectrum disorder (ASD). Tablets (e.g., iPads $\left.{ }^{\circledR}\right)$ have been successfully used as speech-generating devices (SGDs) with individuals with ASD as well as with other developmental disabilities. Three participants with ASD and other developmental disabilities aged between 7 and 10 years participated. According to the author, this field is relatively new and is receiving plenty of attention in practice and scholarship in AAC.

These facts show the relevance of AAC solutions in cases of ID and also emphasize the importance of usability tests. According to the review, there is still a gap because both AAC solutions and usability testing have not been deeply studied in this field yet. This study presents a mobile-based AAC solution conceived as a tool to assist the rehabilitation process of people with intellectual disability (ID). Moreover, the solution was tested for usability, which encompasses user satisfaction when performing certain tasks. It is important to note that this proposal is only a part of the whole process and it should be used together with other tools and theoretical references, such as those based on the Diagnostic and Statistical Manual of Mental Disorders [11]. We based our work on previous experience developing AAC solutions for desktop computers by adapting them for mobile devices, as 
well as considering Web Content Accessibility Guidelines (WCAG) [29] and Mobile Web Best Practices (MWBP) accessibility standards [30].

\section{Materials and Methods}

The study was conducted in Brazil, at the Association of Parents and Friends of Exceptional People. For ethical reasons, we will use the name AP in this text, to refer to this association. A multidisciplinary team at AP works on the rehabilitation of individuals with intellectual disability, multiple disabilities, and autism spectrum disorder. In this study, a pedagogue, a psychologist, a speech therapist, and an occupational therapist conducted the experiments. Twenty-five students participated, all aged 3 to 9 years and who experience a delay in the neuropsychomotor development. The evaluation was developed in six months. The developed solution features activities that are commonly applied by specialists. It is important to note that the AP professionals were involved throughout the development and evaluation processes.

We have received ethical permission for this study and we have consent from AP. It is important to note that we did not directly interact with the children who participated in this study. The AP professionals (specialists) recruited the participants of the experiment and all the interaction with them was made by the specialists. The students were alone with the professionals during the experiment, in the same way as they routinely perform this sort of interaction. Parents were not present during the experiment. It is also important to note that, although this experiment provides important information to the specialists about ID, it should be combined with other tools and theoretical references to provide a complete diagnosis of intellectual disability.

\section{Resources}

It is worth remembering that disability evaluation is multidisciplinary, which means that there is not a single solution, but several instruments that will qualify the process as a whole. Likewise, several aspects should be analyzed, such as adaptive skills, individual health, social participation, and context [31].

The mobile application took into account accessibility recommendations related to thematic coherence, text and image configurability, visual and sound accessibility, touch screen facilities, simple navigation, and clarity [29]. The World Wide Web Consortium (which initially created the Web Content Accessibility Guidelines or WCAG 2.0), through its working group MWBP, established a set of best practices to more specifically address accessibility on devices outlining how to make contents more accessible to people with disabilities. It is important to remark that accessibility of AAC solutions is a prerequisite for students to be able to perceive the AAC solution (this is a contribution from the anonymous review made to the manuscript). Accessibility covers a wide range of disabilities including visual, hearing, physical, speech, intellectual, language, learning, and neurological disabilities. Although those guidelines cover a wide range of situations, they are not able to address the needs of people with all sorts, degrees, and combinations of disabilities. Those guidelines make interface content more accessible to older people, whose skills are constantly changing, and often improve usability for general users.

The device used in the experiments was a 10.1-inch touch screen tablet. The model was the Samsung Galaxy Tab4 SMT530 running the Android operating system. The feature known as vocalizer was used to provide auditory feedback. However, to avoid the "robotized" sound, the specialists were able to record their voice, being something more pleasant and familiar to the student. In addition, the solution used real context images instead of pictographic symbols. Contents and images were displayed using the landscape orientation because it was a suitable framework for the participants. Testing devices with smaller sizes or running other operational platforms, such as Windows Phone and IOS, for example, were not considered in this work.

\section{Modeling}

Software requirements were documented as case study models. Figure 1 shows the use cases related to the educator (caregiver). The educator is able to enter the user data, configure the activities, choose the graphical resources and categories, and edit and save the results, among other tasks.

Figure 2 shows the use cases related to the user. The students interact with the system and perform the activities. It should be emphasized that the students should have the necessary support of the professionals guiding them to perform the activities. Professionals did participate in use case and activities design.

Figure 3 illustrates examples of the activities performed by the students. The main activities are drag and drop and hit the target. Several updates and future refinements should be necessary to consider the progressive inclusion of new activities.

\section{The Solution}

The use of WCAG/MWBP recommendations should be carefully studied because technology cannot be a limitation, preventing more advanced technologies from being a restriction for using it, for example, avoiding some known risks (i.e., usability of small screens/keyboards); taking into account the limitations of the device; using optimized code so that it can be executed on any device; and saving the use of the network (updates), focusing on clarity and simplicity, and customizing autonomy of the battery.

The solution took into account WCAG/MWBP guidelines, providing textual alternatives to any nontext content so that it can be transformed into other forms according to user needs, such as larger font size, auditory feedback, symbols, and simpler language:

(1) Contents are presented in different ways (i.e., a simplified layout) without losing information

(2) Facilitating the listening and viewing of content, including separation of foreground and background

(3) Operable, providing sufficient time to read and use content 


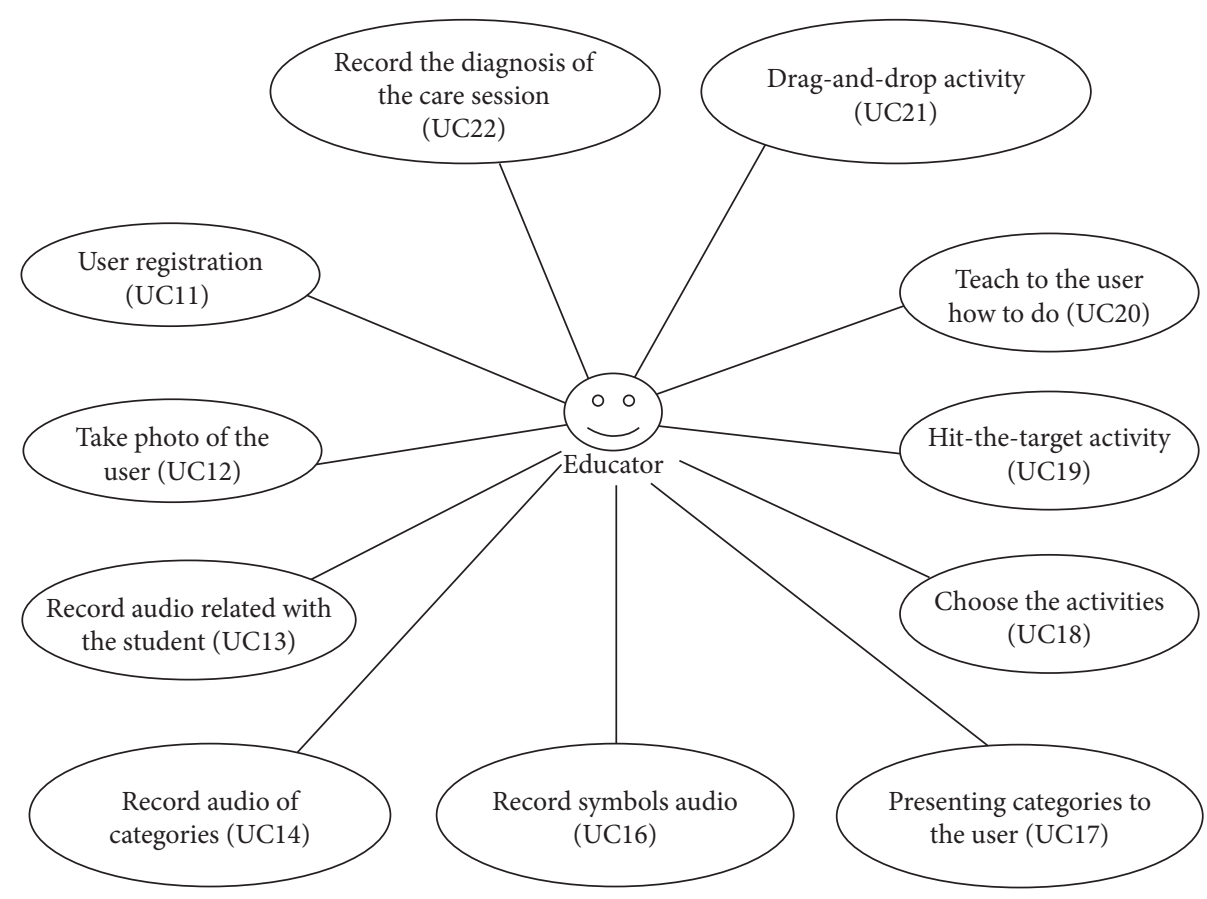

FIgURe 1: Educator case study.

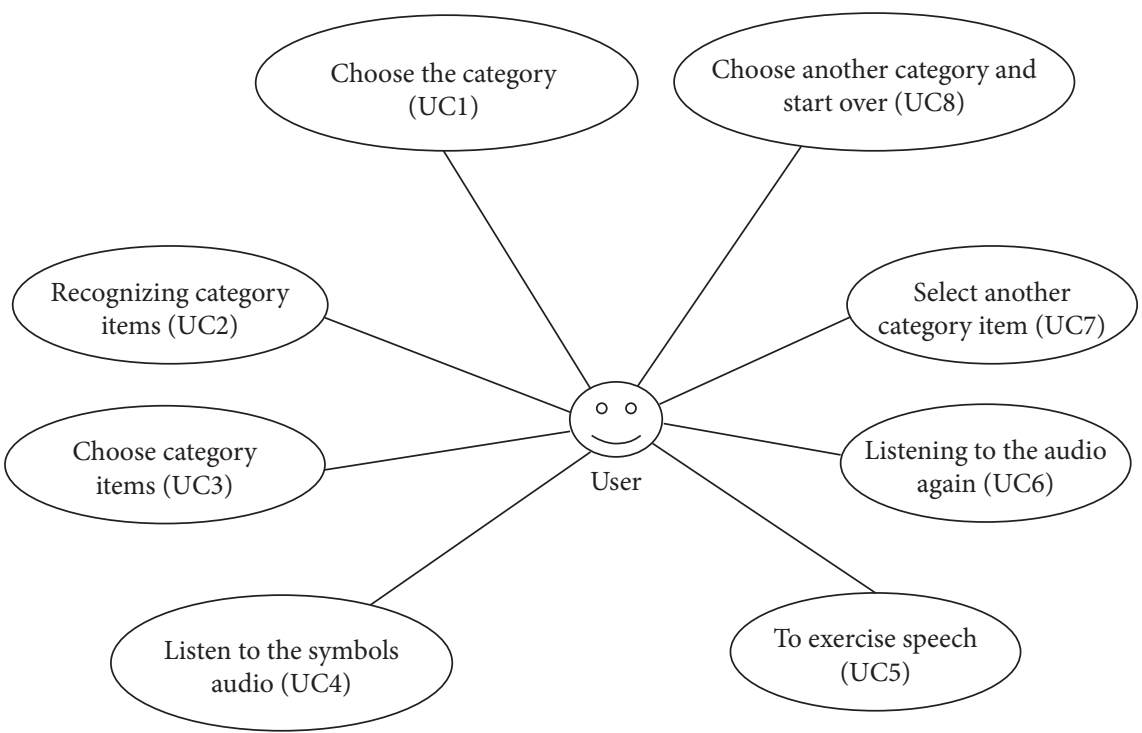

FIgURE 2: User case study.

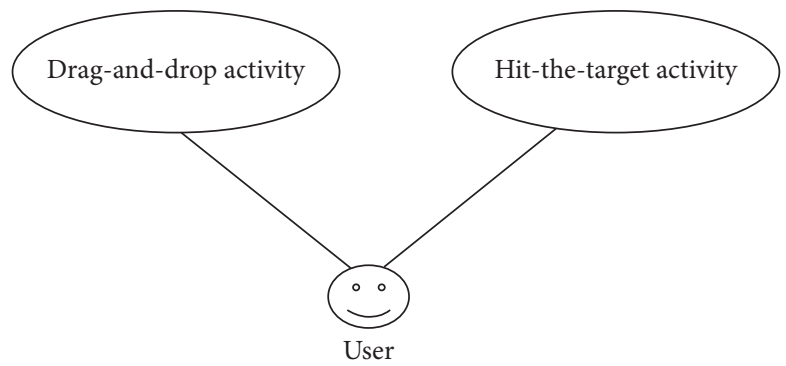

FIgURE 3: Student activities. 
(4) Comprehensible contents, making text content readable and understandable

(5) Helping the user to avoid and correct errors

These WCAG/MWBP guidelines were considered to develop the interface illustrated in Figures 4-9. Textual alternatives were provided next to the symbols, also supported by auditory feedback. In addition, listening and viewing of content were facilitated, including the separation between foreground and background, making contents readable and understandable All the screens are operable, providing sufficient time to read and use the content.

Figure 4 illustrates the welcome screen. The professional should provide a user identification and password to log into the system. It is important to note that the specialists make the login instead of students.

Figure 5 shows the student interface. Student registration (which is performed by the professionals) is necessary to be able to use the application. It is possible to edit and save data for each user, such as name, type of diagnosis, date of birth, date of evaluation, observations, photo, and associated auditory information. It is important to note that this information involves personal data and must be treated with all the necessary integrity and security.

Figure 6 illustrates the specialist interface, which is used to record any relevant data about the student. A picture and the associated auditory information can be recorded through this interface. The specialists can consult this information at any time. Once again, this information involves personal data and must be treated with all the necessary integrity and security.

Figure 7 shows the gallery of images being used, illustrated by symbols and categories, such as Actions, Food, Animals, Toys, Communication, Colors, Fruits, Liquids, Furniture, Vegetables, Clothing, and Transportation.

Figure 8 shows the symbols inside the food category: rice, cookies, beans, pasta, bread, pie, and grape. The name of the student appears in the title bar. When the professional accesses this screen, the student's name will be heard through the vocalizer if the audio option was previously recorded and enabled, consistent with WCAG/MWBP guidelines. By clicking in the "About" (Sobre) option, all the project data (i.e., student, advisor, professionals of AP, and related institutions) is shown. The professional can use the auditory feedback (previously recorded), for each image or symbol.

All images were adapted taking into consideration the screen layout and the specifications of the tablet used in the experiments, making contents readable and understandable, consistent with the WCAG/MWBP guidelines. The professional can record audios for each image; however, only one audio file can be associated with a particular symbol.

The solution also explores one of the conceptual methods of Luria, who seeks to investigate the thought structures of people with suspected intellectual disability [31]. The method consists of classifications and comparison activities. The drag-and-drop activity recreates this method (Figure 9). The goal of this activity is to describe elements or objects by using only one word or a concept (classification) and by

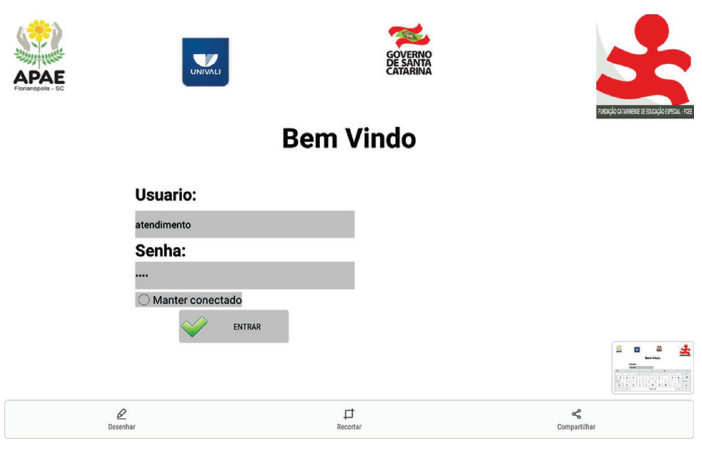

FIgURE 4: The welcome screen.

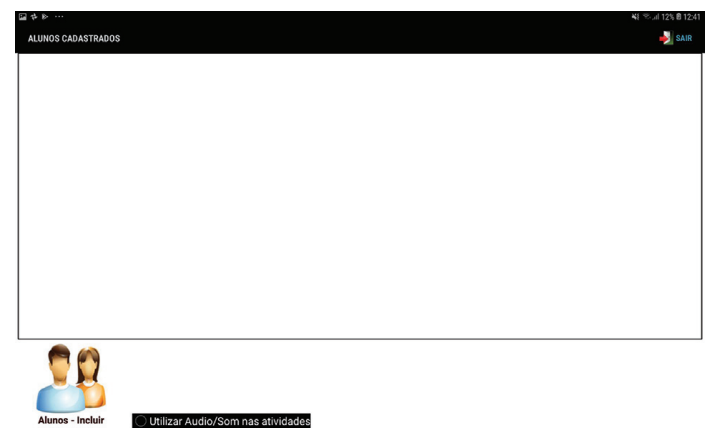

Figure 5: Student data.

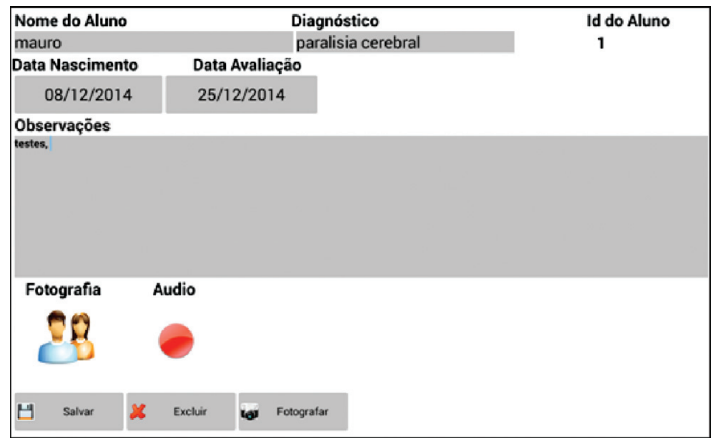

FIgURE 6: Personal data of the user.

explaining which objects could be grouped together and which could not, in some sort of category (comparison). The drag-and-drop activity also explores textual, visual, and auditory information. The professional can configure the items and categories it wants to work on within each session. Through this activity, the student could develop some abilities, such as grouping and connecting the symbols. There are no right or wrong answers during this activity. This method contributes to the diagnosis of an individual with ID and is very helpful in elaborating a rehabilitation program individualized for each person.

To perform this activity, the student must select a symbol (which appears at the top of the screen) by placing it inside of one of the boxes at the bottom part of the screen. This is done by using the touch screen feature of the mobile device. The 


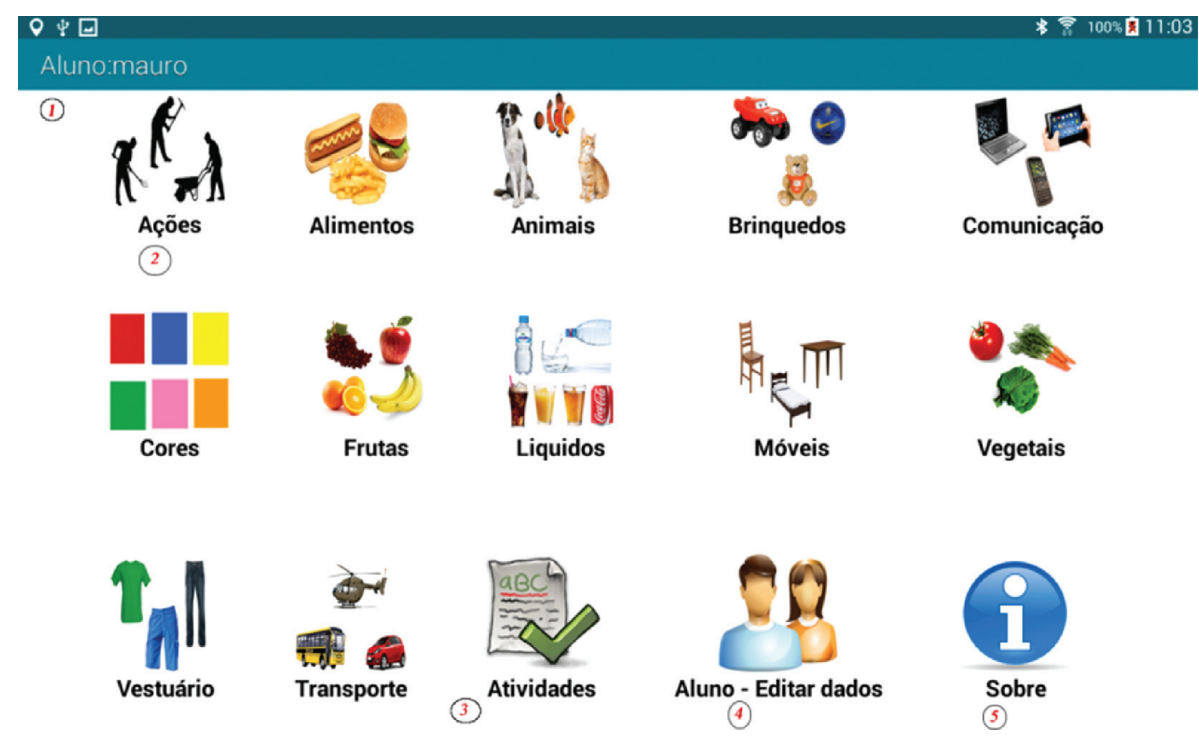

FIGURE 7: Library of symbols and categories.

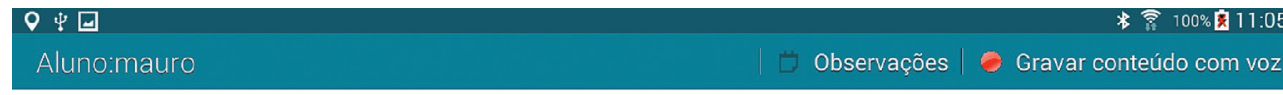

Alimentos

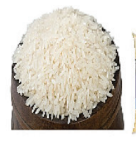

Arroz
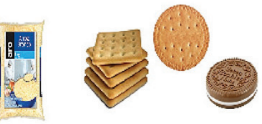

Bolachas

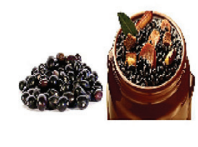

Feijão

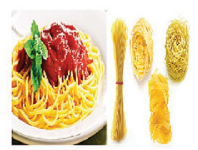

Macarrão

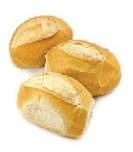

Pão

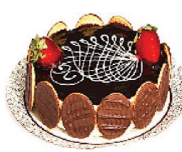

Torta

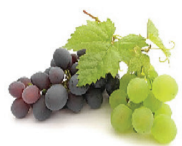

Uva

FIGURE 8: Symbols of the food category.

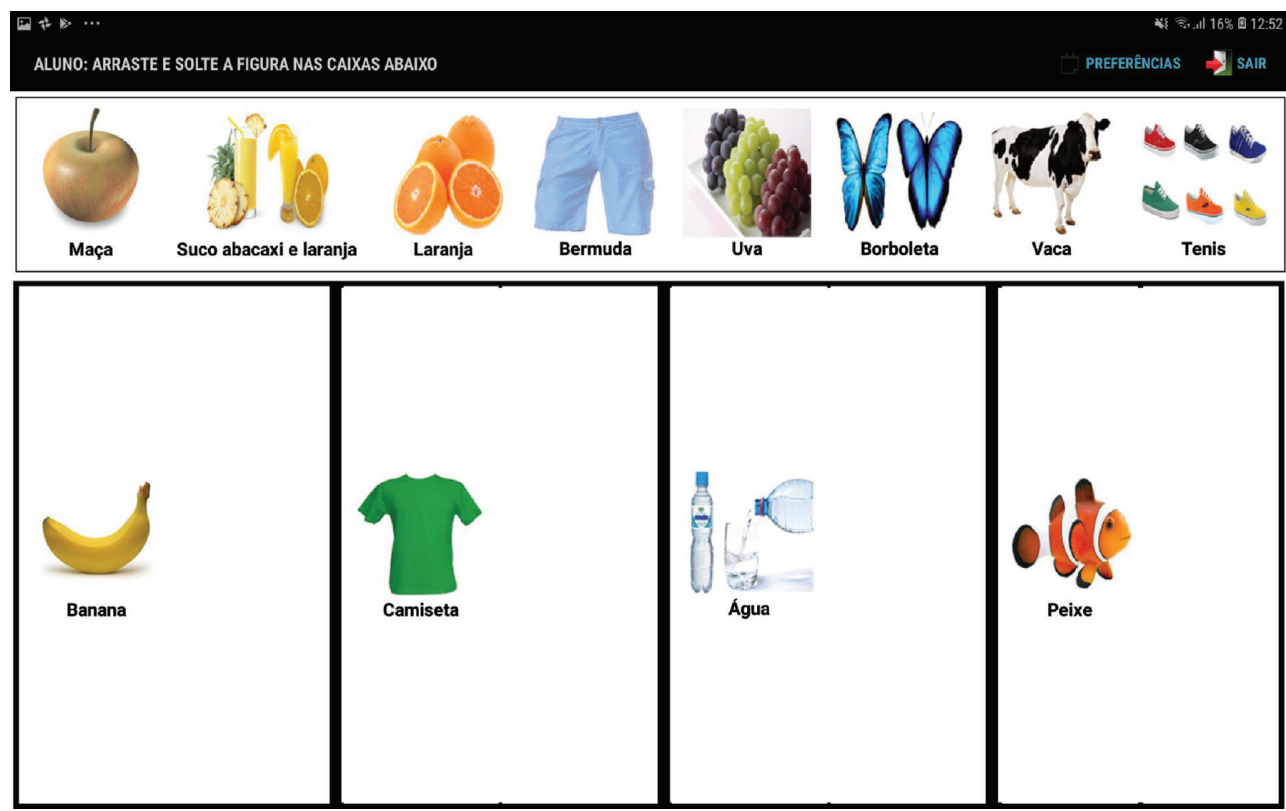

Figure 9: The drag-and-drop activity. 
specialist configures the symbols and categories according to the student's needs. The solution lets the professional adjust symbol size and select the kind and number of categories, also providing an auditory feedback, consistent with WCAG/MWBP recommendations. The quantity and symbol sizes are chosen according to the characteristics of the experiment. It is important to note that there is not a right or wrong answer, and the application does not score or record this information. This experiment provides important information to the specialists and, combined with other tools and theoretical references, will allow them to design and formulate rehabilitation activities.

The hit-the-target activity in Figure 10 was created to analyze the motor skills of the student. The software calculates the time the user takes to select the symbol shown in the top-left of the screen and release it at the bottom-center of the screen. This information could be used later in the drag-and-drop activity to better adapt the tool to users with motor disorders.

\section{Results and Discussion}

Usability evaluation helps developers identify issues related to the user's perception of system performance (effectiveness and efficiency), as well as their satisfaction when performing tasks, given a context of use. Due to the communication difficulties inherent in the subjects of this research, usability evaluations had to be intermediated by the professionals (specialists) who accompanied the students, with the consent of their parents or legal guardians. The results of these evaluations should, therefore, be analyzed, discussed, and understood considering this limitation.

Four specialists performed the usability evaluation at AP: a pedagogue (conducted the study), along with a psychologist, a speech therapist, and an occupational therapist. Twenty-five students participated in the experience: nineteen students with ASD, four with Down syndrome, and two with cerebral palsy. They are aged between 3 and 9 years (10 boys and 15 girls).

Figure 11 illustrates how this activity is traditionally done at AP. The scenario is a simple room, where the specialists spread symbols out on a table with a onemeter diameter. The experiment takes around $10 \mathrm{~min}$ utes. This is the traditional methodology (Figure 11(a)). The specialist should perform the auditory feedback and no other accessibility issue is considered (i.e., the test is practically inaccessible when the student has motor impairments).

Figure 11(b) illustrates the new approach. To provide a new experience, symbols are inserted in the tablet application to do the same activity, but now feature accessibility standards.

The System Usability Scale (SUS) [32] was used to evaluate the tool. The SUS is widely used to evaluate the usability of products and systems experienced by users due to its simplicity and reliability, even when applied to small samples [33]. The SUS questionnaire consists of ten questions regarding the usability of a product or system as a whole, but not referring to its specific parts [32]. The questionnaire intercalates positive and negative statements
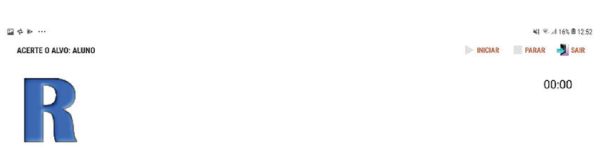

\author{
$\mathbf{R}$ \\ Figure 10: Hit-the-target activity.
}

regarding the usability of the solution being analyzed. Users express their agreement, or not, with respect to each one of the ten statements of the questionnaire by using a Likert scale [34]. The global score can range from 0 to 100 .

In this work, the SUS questions had to be adapted, since the specialists answered the questionnaires, instead of the users, by interpreting their feelings or opinions. The English version of the questionnaire is shown below as it was originally applied in Portuguese:

(1) I think the (Student) would like to use this system frequently

(2) I found the system unnecessarily complex to be used by the (Student)

(3) I think the system was very easy to use by the (Student)

(4) I think the (Student) would need technical support to be able to use this system

(5) I found the various functions of this system well integrated

(6) I thought there was too much inconsistency in this system

(7) I would imagine that most people, under the conditions of the (Student), would learn to use this system very quickly

(8) (I believe) the (Student) found the system very cumbersome to use

(9) I felt the (Student) was very confident using the system

(10) The (Student) needed to learn many things before it could get going with this system

According to Tullis and Albert [35], a SUS score above 68 indicates acceptable usability of the system or product, and a SUS score below 50 indicates unacceptable usability, as depicted in Figure 12.

Table 1 shows the answers to the questionnaire applied to 25 students at AP. The lines located at the bottom part of the table show the median of the SUS score. The answers were grouped according to the disability and levels of impairment. In addition, on the right side of the table, the medians for each item of the SUS questionnaire are presented. Items poorly evaluated in each of the questionnaires are highlighted in yellow.

Initially, by analyzing all 25 students together, we observe a central value (here expressed through the median) of 


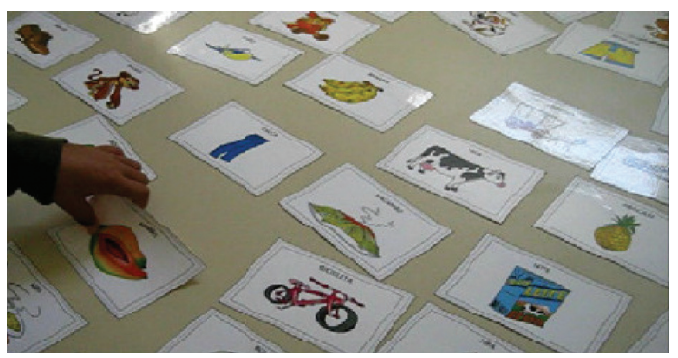

(a)

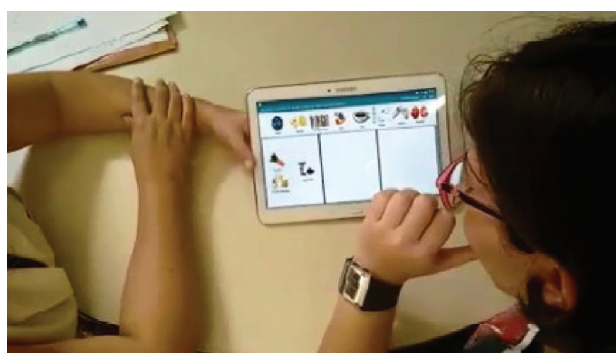

(b)

FIgure 11: Traditional methodology (a) versus the new proposal (b).

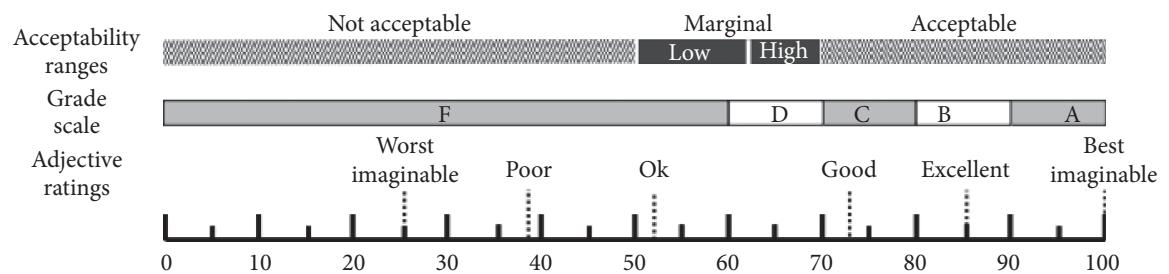

FIgURE 12: Acceptability ranges for SUS scores [35].

TABLE 1: Answers to the SUS questionnaire.

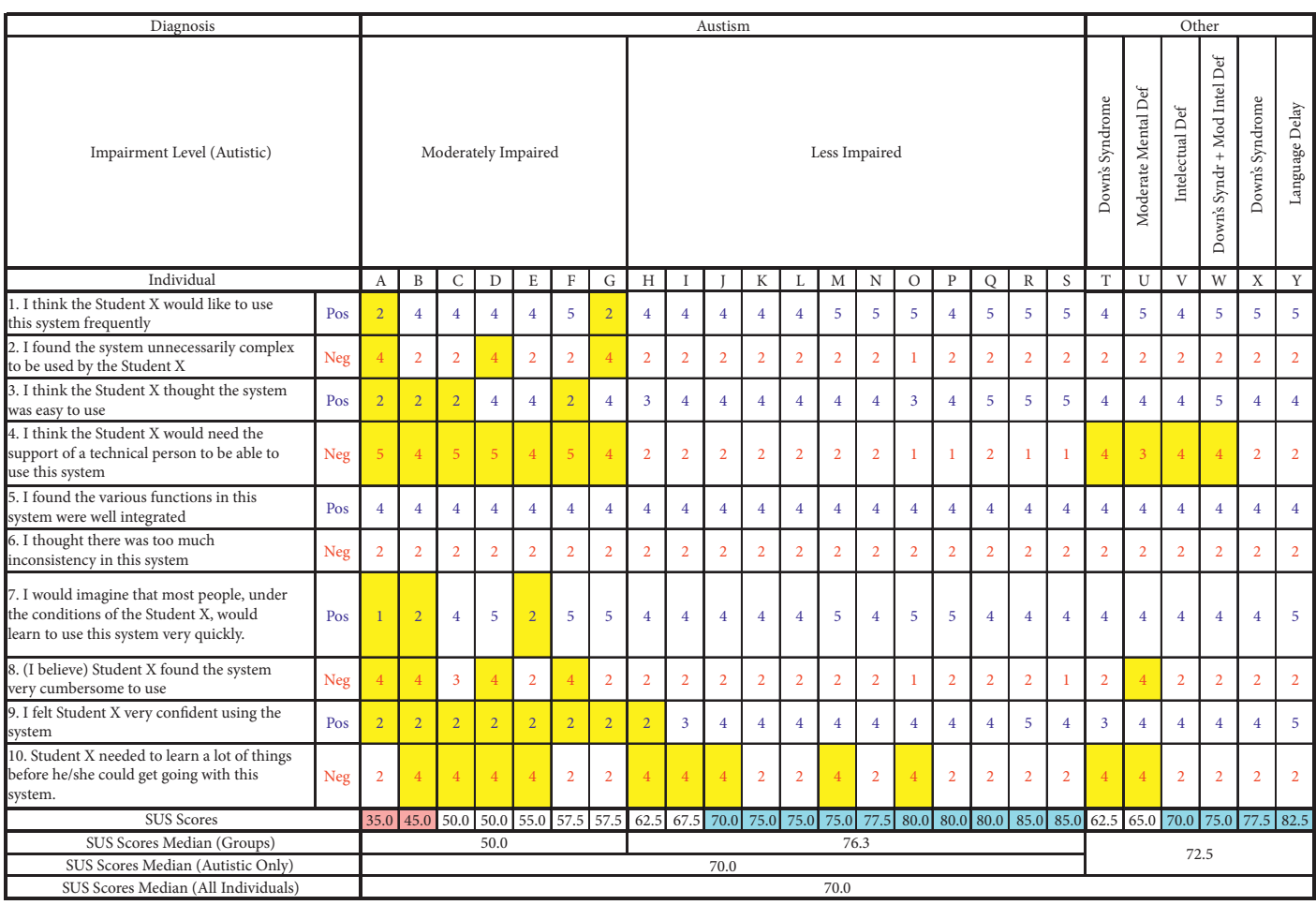

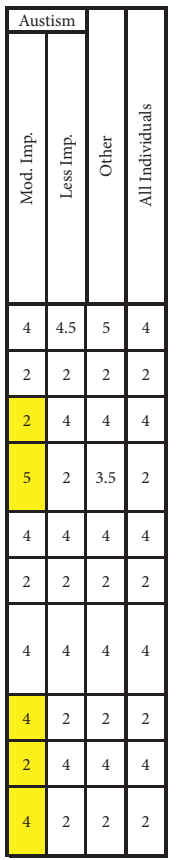

70, which is an "acceptable" usability, according to [26]. Among the 25 students, only two ( 8 percent) presented a "not acceptable" usability (SUS score $<50$ ); fourteen students (56 percent) presented "acceptable" usability (SUS score $>68$ ); and finally, the remaining nine (36 percent) students presented "marginal" usability (SUS score between 50 and 68).
The analysis becomes more interesting when we study separately the nineteen students with ASD and group them into "Less Impaired" and "Moderately Impaired" student categories. We promptly observe the predominance of the poorly assessed items (yellow marks) for the most compromised students with ASD. This is reflected by the significant difference in the SUS scores for the two groups: the 
“Moderately Impaired" group had a median of 50 (limit for nonacceptability), and the "Less Impaired" group showed a median of 76 , which is considered a "good usability," according to [35].

Analyzing the "Moderately Impaired" students, we observe that the worst evaluated items concern to the following aspects of the usability of a system (according to the specialist's perception): (1) need a technical support to use this system; (2) lack of confidence while using the system; (3) perception that the system was not easy to use; (4) perception that the system was very cumbersome to use; and (5) perception that the student needed to learn many things before they could get going with this system. Five of the "Less Impaired" students poorly evaluated the last item (42 percent).

Items 5 and 6 of the SUS questionnaire were well evaluated by the specialists, regardless of the disability. These items linked the integration between the system functions and the system inconsistencies, respectively. Finally, according to the specialists' perception, 23 of the 25 students (92 percent) would like to use the tool frequently.

Previous research also has similarities with our work. Wiley et al. in [24] conducted a study with participants having a variety of disabilities. They registered positive results for "level of engagement" and "ease of use." For lowerfunctioning students or students not previously exposed to tablet technology, scores were lower, but the overall scores remained high based on the 5-point scaling used in the study. Students scored high in the areas of "level of enjoyment" (mean value: 4.47) and "participation" (mean value: 4.19). Scores for "ease of use" (mean value: 3.75 ) and "ability to learn steps and information" (mean value: 3.71 ) were lower.

Yeni et al. in [25] examined the usability of an interactive tablet application designed to teach daily living skills to individuals with intellectual disabilities. Effectiveness, efficiency, and satisfaction aspects were investigated. The results show that using the interactive tablet application in the education of individuals with ID could be an effective method for improving their skills and self-confidence. Teachers' points of view about interaction with the tablet applications were categorized under six themes: effectiveness, usefulness, enjoyment, ease of use, attitudes about future use, and improvements. The teachers felt that the application was "easy" for the students with ID, though they added that learning exercises should be individualized.

Both studies examined the usability of interactive tablet applications designed for individuals with intellectual disabilities. The authors had positive results for "level of engagement" and "learning to use." For lower-functioning students, the "ease of use" and "ability to learn" scores were lower. In addition, the professionals concluded that more studies about usability are necessary in cases of ID.

The source code of the AAC Mobile software is open to users and the developer's community and is available at

https://www.dropbox.com/sh/qhtumlpoxxu7aeu/ AAAwriSZ_tC5h07op2nNzL0_a?dl=0.

This study has the ethical approval of the University of Vale de Itajai, Santa Catarina. The Ethics Committee in
Research with Human Beings, under the Introduction to Ethics Assessment Certificate (CAAE), approved the "Development of alternative and augmentative communication tools to people with motor and speech disorders," and we had the consent of participants and/or their parents.

\section{Conclusions}

According to UNESCO, inclusive education implies an ongoing process of school improvement in order to utilize available resources, especially human resources, to promote the participation of all students in the community environment. In this scenario, information and communication technologies can play an important role by increasing and improving services dedicated to disabled people. Effective digitally delivered interventions are attractive. However, the number and availability of solutions are still insufficient for professionals and users. On the other hand, recent developments in mobile technology, such as smartphones and tablets, have provided important new ways of communicating. The wide availability of these powerful portable networking technologies has changed our ways of interacting with our peers.

In Brazil, there is a gap between the availability of solutions and the needs of professionals and users with ID. This work described an AAC solution conceived for intellectual disability. It was designed for a tablet device, based on our first work developed for cerebral palsy students [36], and development and modeling issues were discussed. It is important to note that the development was guided by a participatory design, being carried out in partnership with a multidisciplinary team from AP. A pedagogue, a psychologist, a speech therapist, and an occupational therapist conducted the experiments. Twenty-five students aged between 3 and 9 years participated. The SUS was used to evaluate the tool in terms of usability. The solution showed good usability, with a global score of 70. Among the SUS questions, "the student's desire to use the system" stood out positively. This is probably related to the attraction that mobile devices generally arouse in children and young people. The application also stood out positively for "not needing technical help to be used." On the other hand, it was noticed that "training should be provided before using the application." For the group of moderately impaired students with ASD, however, in terms of usability, the application did not perform so well, with a median of 50 (limit for nonacceptability). For this group of students, the application showed to be too complex and difficult to learn and use. However, even with these difficulties, they showed a strong desire to use the system. It was inferred that, for those students, the application should be used with the assistance of a professional or a family member.

It was concluded that the proposed AAC solution has potential as an educational tool, being useful in institutions that work with students with intellectual disabilities and communication disorders. For its best effectiveness, however, the need for third-party help is clear. Finally, we should clarify that this study was not intended to evaluate the efficiency of the computational solution developed in comparison with the traditional card-based methodology. It was 
also not our intention to analyze the influence of the solution's use on therapy activities impact on ID participants.

Future works will consider the inclusion of new activities, enhancing support for the rehabilitation process. In addition, the age ranges and heterogeneity of participants should be further explored. As the study relied on the use of auditory feedback, it would have been useful to explore the auditory status of the participants. The incidence of hearing loss in individuals with Down syndrome should also be considered.

It is important to continue investing in the development of alternative communication resources for special education. Research into digital interventions should include people with intellectual disability, centering their participation in the development and evaluation stages. The authors are not aware of any application with similar purpose being developed and used in special education institutions in Brazil.

\section{Data Availability}

The data generated or analyzed during this study are available on Google Drive at https://drive.google.com/drive/ u/1/folders/1ifgY6zo71-MUv6Ht4aBUOIRqjf-1_HN_.

\section{Conflicts of Interest}

The authors declare that there are no conflicts of interest regarding the publication of this paper.

\section{Acknowledgments}

The authors thank Fundação de Amparo à Pesquisa e Inovação no Estado de Santa Catarina (FAPESC) (Grant numbers 2015TR300, 2019TR610, and 2020TR729) and the Brazilian National Council of Scientific \& Technological Development CNPq (Grant number 309429/2015-3). The authors also thank Fundação Catarinense de Educação Especial (FCEE) and Fabiana de Melo Giacomini Garcez Garcez, Pedagogue, from AP. This study was financed in part by the Coordenação de Aperfeiçoamento de Pessoal de Nível Superior - Brasil (CAPES) - Finance Code 001.

\section{References}

[1] WHO-World Health Organization, "World report on disability," http://www.who.int/disabilities/world_report/ 2011/report/en/index.html, World Health Organization, Geneva, Switzerland, 2011, http://www.who.int/disabilities/ world_report/2011/report/en/index.html.

[2] L. Sartoretto and R. C. Bersch, Recursos Pedagógicos Acessíveis. Brasil. MEC. Secretaria de Educação Especial. Educação Especial na Perspectiva da Inclusão Escolar. Recursos Pedagógicos Acessíveis e Comunicação Aumentativa e Alternativa. Brasília, Secretaria de Educação Especial, Brasília, Brazil, 2010.

[3] IBGE Instituto Brasileiro de Geografia e Estatística, Uma Análise das Condições de Vida da População Brasileira, Instituto Brasileiro de Geografia e Estatística, Rio de Janeiro, State of Rio de Janeiro, Brazil, 2010, http://www.ibge.gov.br/ home/estatistica/populacao/condicaodevida/indicadoresminimos/ sinteseindicsociais2012/default.shtm.

[4] Cartilha do Censo, Pessoas com Deficiência. Secretaria de Direitos Humanos da Presidência da República (SDH/PR). Secretaria Nacional de Promoção dos Direitos da Pessoa com Deficiência (SNPD). Coordenação-Geral do Sistema de Informações sobre a Pessoa com Deficiência, SDH-PR/SNPD, Brasília, Brazil, 2010.

[5] S. Hayhoe, "Utilising mobile technologies for students with disabilities," in Commonwealth Education Partnerships 2015/ 16. Commonwealth Education Partnerships. Nexus Strategic Partnerships, R. Jones-Parry, Ed., Commonwealth Secretariat, London, UK, 2015.

[6] D. McNaughton and J. Light, "The iPad and mobile technology revolution: benefits and challenges for individuals who require augmentative and alternative communication," Augmentative and Alternative Communication, vol. 29, no. 2, pp. 107-116, 2013.

[7] R. Sheehan and A. Hassiotis, "Digital mental health and intellectual disabilities: state of the evidence and future directions," Evidence Based Mental Health, vol. 20, no. 4, pp. 107-111, 2017.

[8] R. L. Schalock, S. A. Borthwick-Duffy, V. J. Bradley et al., Intellectual Disability: Definition, Classification, and Systems of Supports, American Association on Intellectual and Developmental Disabilities, Washington, DC, USA, 11th edition, 2010.

[9] A. M. Cook and J. M. Polgar, Assistive Technologies: Principles and Practice, Mosby/Elsevier, Maryland Heights, MO, USA, 2015.

[10] Disability Survey, Wellington, Statistics New Zealand, 2007. http://www.stats.govt.nz/browse_for_stats/health/disabilities/ disabilitysurvey2006_hotp06.aspx.

[11] American Psychiatric Association, Diagnostic and Statistical Manual of Mental Disorders, American Psychiatric Association, Washington, DC, USA, 2014, http://www.dsm5.org/ psychiatrists/practice/dsm.

[12] R. Bersh, Introdução à Tecnologia Assistiva, Assistiva-Tecnologia e Educação, Porto Alegre, Brazil, 2013, http://www. assistiva.com.br/Introducao_Tecnologia_Assistiva.pdf.

[13] ASLA-American Speech-Language-Hearing Association, Augmentative and Alternative Communication, ASLAAmerican Speech-Language-Hearing Association, Rockville, MD, USA, 2012, http://www.asha.org/public/speech/ disorders/AAC.htm.

[14] D. Branson and M. Demchak, "The use of augmentative and alternative communication methods with infants and toddlers with disabilities: a research review," Augmentative and Alternative Communication, vol. 25, no. 4, pp. 274-286, 2009.

[15] MEC. A, "Política nacional de educação especial na perspectiva da educação inclusiva," 2008.

[16] Aragonese Portal, 2019, http://arasaac.org/.

[17] Mind for better mental health, 2020, https://www.mind.org. $\mathrm{uk} /$.

[18] Mental Health, 2020, http://www.rcpsych.ac.uk/healthadvice/ atozindex.aspx.

[19] https://www.mencap.org.uk/familyhub, 2020.

[20] Projeto Participar, 2019, http://www.projetoparticipar.unb. br/.

[21] J. L. Matson and M. Shoemaker, "Intellectual disability and its relationship to autism spectrum disorders," Research in Developmental Disabilities, vol. 30, no. 6, pp. 1107-1114, 2009.

[22] P. Williams and S. Sidharth, "Mobile devices and people with learning disabilities: a literature review," International Journal 
of Computer Science and Mobile Computing, vol. 8, no. 2, pp. 34-43, 2019.

[23] A. Ebert and S. Parveen, "Use of iPad and Mobile Devices in Children with Autism Spectrum Disorders: A Systematic Review," The Journal of Communication Disorder, vol. 3, pp. 1-18, 2018.

[24] B. Wiley, D. Cameron, S. Gulati, and A. Hogg, "Exploring the use of tablets (iPads) with children and young adults with disabilities in Trinidad," Disability and Rehabilitation: Assistive Technology, vol. 11, no. 1, pp. 32-37, 2016.

[25] S. Yeni, K. Cagiltay, and N. Karasu, "Usability investigation of an educational mobile application for individuals with intellectual disabilities," Universal Access in the Information Society, pp. 1-14, 2019.

[26] D. Cáliz, L. Martínez, X. Alamán, C. Terán, and R. Cáliz, "Usability testing in mobile applications involving people with down syndrome: a literature review," Computer Science \& Information Technology, vol. 6, no. 7, pp. 1-11, 2016.

[27] A. Carniel, C. D. M. Berkenbrock, and M. d. S. Hounsell, "Um mapeamento sistemático sobre o uso da comunicação aumentativa alternativa apoiada por recursos tecnológicos," Revista Brasileira de Computação Aplicada, vol. 9, no. 2, pp. 84-98, 2017.

[28] Alzrayer and M. Nouf, The Effects of Using iPads ${ }^{\circledR}$ in Teaching Multistep Social-Communication Skills to Children with Autism Spectrum Disorder, Texas Tech University, Lubbock, Texas, 2017.

[29] W3C, 2017, https://www.w3.org/.

[30] Rabin J. and Mccathienevile C., Mobile Web Best Practices 1.0, W3C, 2008, http://www.W3.Org/Tr/Mobile-Bp/.

[31] I. C. Palangana, "Desenvolvimento e aprendizagem. Em piaget e vigotsk: a relevância do social. 6 ," 2015.

[32] J. R. Lewis, "IBM computer usability satisfaction questionnaires: psychometric evaluation and instructions for use," International Journal of Human-Computer Interaction, vol. 7, no. 1, pp. 57-78, 1995.

[33] J. Brooke, "SUS-A quick and dirty usability scale," Usability Evaluation in Industry, vol. 189, no. 194, pp. 4-7, 1996.

[34] A. Bangor, P. Kortum, and J. Miller, "Determining what individual SUS scores mean: adding an adjective rating scale," Journal of Usability Studies, vol. 4, no. 3, pp. 114-123, 2009.

[35] T. Tullis and B. Albert, Measuring the User Experience: Collecting, Analysing, and Presenting Usability Metrics, MK Elsevier, Amsterdam, Netherlands, 2013.

[36] C. E. Saturno, A. R. G. Ramirez, M. J. Conte, M. Farhat, and E. C. Piucco, "An augmentative and alternative communication tool for children and adolescents with cerebral palsy," Behaviour \& Information Technology, vol. 34, no. 6, pp. 632-645, 2015. 